\title{
3D LANDSCAPE OBJECTS FOR BUILDING INFORMATION MODELS (BIM)
}

\author{
M. Fritsch ${ }^{1 *}$, C. Clemen $^{2}$, R. Kaden ${ }^{3}$ \\ ${ }^{1}$ Chair of Surveying and Geoinformatics, Erfurt University of Applied Sciences, Erfurt, Germany - martin.fritsch@ fh-erfurt.de \\ ${ }^{2}$ Dresden University of Applied Sciences, Dresden, Germany - christian.clemen@htw-dresden.de \\ ${ }^{3}$ Chair of Surveying and Geoinformatics, Erfurt University of Applied Sciences, Erfurt, Germany - robert.kaden@ fh-erfurt.de
}

\author{
Commission VI, WG VI/10
}

KEY WORDS: Building Information Modeling, Landscape Objects, Surveying, Location Plan, Georeferencing, IFC, Integration

\begin{abstract}
:
Building Information Modeling (BIM) is a method for the digital collaborative design, construction and operation of buildings. However, in order to realize a complete view on needed work and expenses of a building, the surrounding landscape elements must be considered as well. Within this paper, the BIM authoring tool Autodesk Revit and the open BIM data model and exchange format Industry Foundation Classes (IFC) has been investigated for its capability to represent landscape elements like a terrain model, retaining walls, and ways. Therefore, a feasibility study has been carried out including the surveying of real-world landscape objects like terrain, buildings, ways and paths, playgrounds, and retaining walls, in order to use actual existing objects instead of idealized, theoretical elements. The aim was to develop and evaluate a workflow from the surveying over the modeling in BIM-able software to the export of an IFC data file. Therefore, the general modeling concepts of BIM and their suitability and limitations for representing landscape elements has been investigated. Experiences made within the project are discussed and first solutions and concepts are recommended. In addition, this paper reports from the buildingSmart International working group "Site, Landscape, and Urban Planning", their current work and future goals, in order to extend IFC for landscape objects. Additionally, a concept for level of information need referring to landscape elements is shown.
\end{abstract}

\section{INTRODUCTION}

"Building Information Modeling" (BIM) is more than just a technological improvement; it is a technological, organizational and cultural paradigm shift. The current governmental initiative "Digital Planning and Building 4.0" in Germany forces the usage of digital models, so-called virtual clones of the planned structures including a common data environment (CDE), instead of using Computer Aided Design (CAD)-based drawings with unmanaged documents. Such an information model has to be created, managed and maintained and used during the entire lifecycle of the building, from the design phase through the planning and construction phase to the operation phase. E.g. the Federal Ministry of Transport and Digital Infrastructure in Germany prescribe mandatory usage of BIM for public infrastructure projects by 2020 (BMVI 2015).

However, a big challenge in applying the BIM method is the planning of new quarters in its site context, in order to include the complete work and costs for buildings. Also, the maintenance of existing real estate requires detailed information about the related landscape. Thus, an integrated planning or maintenance also requires information deliverables including the terrain, connection lines for telecommunication, fresh water, wastewater and gas as well as structures like roads and ways, retaining walls, terraces and utility space and even plants. Products and services related to site planning (earthwork, paving, planting, etc.) include a considerable proportion of construction and operation costs and therefore must be part of the information that is managed in the CDE. However, BIM authoring software like Revit or the open data model and exchange format Industry Foundation Classes (IFC) were mainly developed for buildings and are poorly suitable for modeling landscape objects so far.

Although Geographic Information Systems (GIS) or CAD can be used to model landscape and its exterior objects, however, the connection or transfer of landscape objects into the BIM methodology is not as easy as it seems. The BIM method with its tools and data exchange format IFC is not well equipped in terms of landscapes and exterior objects. According to OUELLETTE (2018), "Landscape Architecture and Open Space Planning have so far played small roles in the digitization of the German construction industry". Reasons for this might be the missing demand for landscape objects in building or infrastructure projects so far, missing tools to generate welldefined landscapes or exterior objects in the BIM environment, and missing standards and definitions. However, landscape modeling in connection with BIM become more important to close the gap between buildings and infrastructure projects as well. Beside the buildings, constructions like bridges, roads, tunnels and railways as well as the surrounding terrain and welldefined landscape objects like ways, utility spaces, retaining walls and plants are needed to analyze, simulate and calculate its influences and expenses within the project. Moreover, Landscape Information Modeling (LIM) within BIM provides a better understanding of a planned project by the stakeholders and the public and provides opportunities for complete new integrated simulations to investigate e.g. airflows, noise, temperature, or water usage.

The aim of this paper was to investigate the suitability and limitations of general modeling concepts of BIM in relation to landscape elements. In this context, chapter 2 "Related Work"

* Corresponding author 
highlights current work in the field of landscape modeling and BIM. In Chapter 3 "Feasibility Study", the implementation from the surveying over the modeling in BIM-able software to the export of an IFC data file is explained based on a practical project. In addition, the experiences, challenges, solutions and other deficiencies related to the modeling concept of BIM are discussed. Due to the limitations in the modeling of outdoor elements, chapter 4 deals with the formalization of landscape elements as a basis for future work. Therefore, a first concept of level of information need and concept of a property server for PDT's and geoPDT's are presented. The last chapter summarizes the first project findings and results and provides information on future work.

\section{RELATED WORK}

The idea to implement landscape elements for BIM already exists for a few years; however, there is a low amount of related work of the scientific community so far.

\subsection{Topographical Modeling in BIM}

RÜCKER (2017) investigated various ways to convert or link landscape elements like digital terrain models or topographic data into BIM software, mainly using Autodesk Revit. Within this paper, a terrain model based on LandXML format was used. The data import into Revit was improved for considering break lines using the integrated development environment Dynamo. In addition, the lossless export of the data into the IFC format was investigated with partly positive results.

ABDIRAD (2015) investigated the IFC data model to find ways of modeling landscape elements. It is mentioned that there are only the entities IfcGeographicElement and IfcSite, which can be used for modeling landscape elements. There is also a predefined property set called Pset_SiteCommon that includes attributes like buildable area, total area or building height limit. In his paper, it is concluded that the IFC schema has very limited landscape elements and site functions and no predefined taxonomy for hardscape and landscape objects. ABDIRAD (2015) appeal for more research to develop landscape elements and their attributes inclusive taxonomies for classifying.

CLEMEN (2019) developed new tools to check and convert geospatial data to IFC. Most IFC models are insufficiently georeferenced. Therefore, various ways to georeference objects has been investigated. Likewise, they developed a tool to convert points, break lines, triangulated irregular networks and surfaces of composite polygons into existing IFC entities like the IfcGeometricCurveSet, IfcShellBasedSurfaceModel, IfcTriangulatedFaceSet, IfcSite, and IfcGeographicElement. This both tools (IfcGeoRefCheckerTool and IFCTerrain) can be downloaded on http://www.dd-bim.org/?page_id=31 (DDBIM 2019). Furthermore, another tool is under construction that allows converting survey location plans from CAD to IFC to create generic IFC objects that linked to volume-based objects and property sets. These tools will improve the conversion and modeling of landscape elements in IFC.

\subsection{Product Data Template and Product Data Sheet}

WIK et. al. (2018) describes a concept to standardize landscape objects to connect buildings, infrastructure and constructions with the landscape. They developed spreadsheets, which includes important features and attributes of landscape objects. The Norwegian initiative and the British Landscape Institute designated these spreadsheets as Product Data Template (PDT). Likewise, they describe Facility, Zone, Terrain, Outdoor Equipment, Vegetation and Construction as main objects for the PDT's with its own definitions and object hierarchy.

In addition to PDT's, the LANDSCAPE INSTITUTE (2016) defined Product Data Sheets (PDS). According to DESIGNING BUILDINGS WIKI (2019), "A Product Data Sheet summarises the performance and other technical characteristics of each construction product, material or component according to specific regulatory, market or client-specific requirements that have been incorporated in the template's mechanism".

\subsection{Extending IFC for Infrastructures}

buildingSMART International (bSI) forces and guides the ongoing development of the open, standardized data model and file format specification Industry Foundation Classes (IFC). Within the last years, the German federal ministry of transport and digital infrastructure started projects helping to extend IFC. A group called IFC Infra supervise and manage the different IFC projects in Germany (IFC INFRA 2019). The group consists of experts from various, related domains in industry, government and research.

IFC Infra accompanied the work on IFC-Bridges to extend the IFC data model for a detailed representation of bridges. This project already finished in 2018 and is now under revision by the international community. Furthermore, IFC Infra accompanied the implementation for railways for IFC called IFC-Rail. In 2019, the expert group of IFC-Rail have presented the latest progress at the bSI Standards Summit in Düsseldorf, Germany including a railway feasibility study in IFC. In summer 2017, IFC Infra began to work on the IFC extension for roads, the IFC-Road project. The last group of IFC Infra is working on the implementation of tunnels for IFC, called IFCTunnel. These projects including new extensions of IFC will inspire and push BIM in practice; however, all these works are focused on large infrastructure projects and do not address to implement elements for representing urban furniture, recreation and leisure or plants in IFC.

By the end of 2018, a new bSI working group "IFC for Site, Landscape, and Urban Design" has been founded, working on new methods to describe and model landscape objects within the BIM methodology and IFC. Especially methods to model plants and other landscape objects, but also the definition of the Level of Information Need (LOIN) for landscape models in IFC is object of work (refer to chapter 4.1). The results of the research presented in this paper show the problems and depict the gaps and needs for modeling landscape objects within BIM. Therefore, the conclusions of the feasibility study are an important input and flows directly into the work of the bSI group "IFC for Site, Landscape, and Urban Design".

\subsection{Extending IFC for Landscape}

The IFC data model already includes mechanism and entities to model landscape objects for LIM. The entity IfcGeographicElement shall represent all geographical elements including furnishing and vegetation elements, e.g. fences, bus shelters, and trees (ABDIRAD 2015). However, OUELLETTE (2018) stated that there is still a lack of knowledge for site, landscape, and urban design in the IFC schema. For example, 
there is no entity or class to model plants with their properties in IFC. The only way to implement plant-objects in IFC is to define user-defined property sets. Consequently, the IFC data model needs more opportunities to model landscape specific entities.

In December 2018, a new buildingSMART International IFC working group for Site, Landscape, and Urban Planning has been founded, with the goal to define new standards and regulations of modeling landscape elements in the future. The group consisting of various domains of economics and research and develop new concepts. Main topics are the definition of general requirements of landscape elements, opportunities to model landscape elements in BIM-able software, the creation of new entities for IFC to model landscape objects and the definition of short-term solutions like the definition of property sets for the IFC data model to import or export data.

At the buildingSMART International Standards Summit 2019 in Düsseldorf, Germany, the expert group came together and discussed a template of requirements for retaining walls, stairs and plants. Similar to the product data template of the British Landscape Institute and the Norwegian initiative, the bSI group defined general requirements in the form of a spreadsheet. For example, the spreadsheet of plants includes categories for the element type, manufacturer, main item data, item data, location, morphology, sustainability, maintenance and miscellaneous. These categories have more detailed subcategories to describe the element exactly. Currently, these spreadsheets are a preliminary draft and have to be reviewed.

These requirements will be the basis to define new property sets and IFC elements. The target is a clearer view of how the site/landscape/urban design is connected to buildings and infrastructure and how the resulting work can be delivered as bSI standard. One strategy can be the creation of a new IFC domain with entities, e.g. ifcTree, ifcBush, etc.) including welldefined attributes for describing landscape objects. Another strategy would be the development of property sets to model exterior elements in IFC. The project is expected to end in April 2020.

\section{FEASIBILITY STUDY}

\subsection{Introduction}

In order to investigate modeling real landscape objects within BIM, a feasibility study has been carried out in 2017. The project area is a hotel and restaurant with a spacious recreation area situated in the Saxon Switzerland, Germany. The main building itself was already modeled in BIM.

In order to use actual existing objects instead of idealized, theoretical elements, the feasibility study include a survey campaign to capture as built landscape in a reasonable level of detail and geometric accuracy. Although real landscape elements such as terrain data, ways, cables and metadata of heights already exist within geodata infrastructures, the level of detail and geometric accuracy is not sufficient to model construction elements from it, in order to investigate the BIM methodology for real world landscape modeling. Only the surveyed real-world data has depicted the variety and particularity of the construction of landscape elements in contrast to building components. Representatives of different kinds of topographic objects has been measured using a total station.

In advance, the usage of existing standards for modeling topographic objects such as CityGML or LandInfra has been discussed. However, although such data models are very suitable for modeling landscape objects using boundary representation, they are not appropriate for modeling large-scale construction elements using parametric (volumetric) components. That means, the advantages of BIM i.e. direct calculation of construction material, number and dimensioning of construction elements, etc. get lost. However, since the aim of the project is to take advantage of the construction component-oriented objects for the planning and the maintenance of landscape of real estates, the existing GIS standards has not been considered.

\subsection{Workflow}

Since surveying and BIM come from different domains, there is no software or software suite, which provides a data flow without media break. Therefore, a number of different software and its components has been used during the project. Because of this, it was important to test and evaluate preferably export formats in order to minimize the loos of information. The workflow represented in this paper on how to convert surveyed objects into IFC is not a general solution, however, it depicts a possible variant.

The first task was to survey the topography including landscape elements like the digital terrain model, complex retaining walls, terraces, ways, stairs, a barefoot walk, a bench around a tree, a playground, and stone sculptures (Figure 1). Therefore, a total station and GNSS has been used creating a *.gsi file.

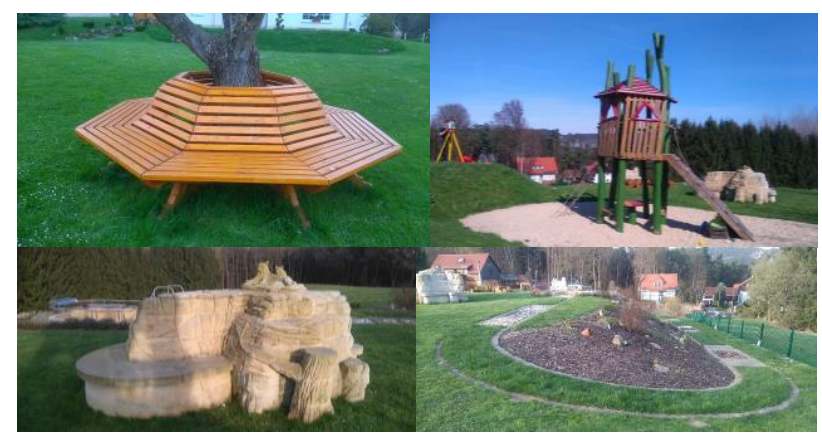

Figure 1 Special landscape elements on the terrain

Based on the survey data, a digital location plan with height information has been created using the surveying software GEOgraf. In order to come from the surveying domain to the BIM domain, the location plan has been exported to DXF which lead to a significant loos of information. However, the data has been successfully imported to AutoCAD to prepare the data within two separate files, the terrain points for creating a Digital Terrain Model using AutoCAD Civil 3D and the landscape elements for the import into Revit. Afterward, the project was georeferenced by using a GNSS pass point and an orientation. To combine the georeferenced project with the existing BIM model of the main building, it is important that both files have been georeferenced in the same coordinate reference system. If the project base points in both projects are identical, the method "Auto - Project Base Point to Project Base point" link both models together. By rotating around the project 
base point, the building model got its correct alignment within the project. Using the imported location plan data, the landscape objects have been modeled using the BIM modeling methodology within the BIM authoring tool.

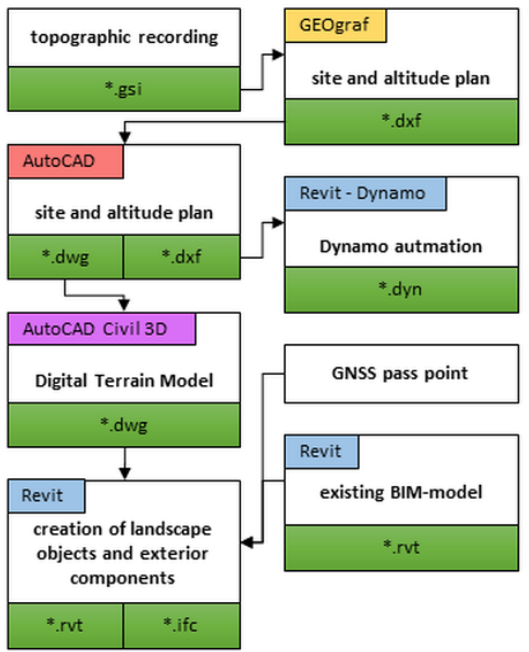

Figure 2 Workflow including used software and exchange formats

Finally, the model was exported to an IFC file. Because of the workflow (Figure 2), the special landscape elements and the authoring software, it was a big challenge to convert the data into the IFC format. Consequently, within this project, it was not possible to pass through the data to an IFC model without losing information. One reason was that many Revit families do not exist in the IFC model. Likewise, Revit parameter was transferred into IFC in a confusing way. The definition of userdefined property sets in IFC mostly solved this problem.

In addition, the Site Designer in Revit was tested to create and modify the terrain and some surface-based landscape objects like paths or parking areas. However, modeling 3D real world landscape was not possible using the current version. Moreover, during the work with Site Designer, failures occurred in the model, which could not be solved so far. The plugin for Revit did not bring a benefit for this feasibility study.

\subsection{Challenges in modeling}

3.3.1 Terrain Modeling: The topography at the project site in the Saxon Switzerland is quite changing in height, which shows the limits in modeling the terrain using the BIM software Revit. The program only allows the processing of terrain point data that will be triangulated to a terrain surface. For a correct representation of the landscape, especially for objects that are surrounded by the terrain like retaining walls, it is important to introduce break lines into the terrain model. However, the import and processing of break lines is not supported within the software Revit 2017. Therefore, it was not straightforward to model elements on or in the terrain since the terrain mostly cuts the landscape elements or even hides the view (Figure 3).

In order to realize the project, a workaround has been carried out. Break lines were cut at a distance of 20 centimeters to create new 3D points. These created points were merged into the terrain point cloud data set, which was triangulated again. Thereby, it was possible to force the course of the terrain along the landscape elements.

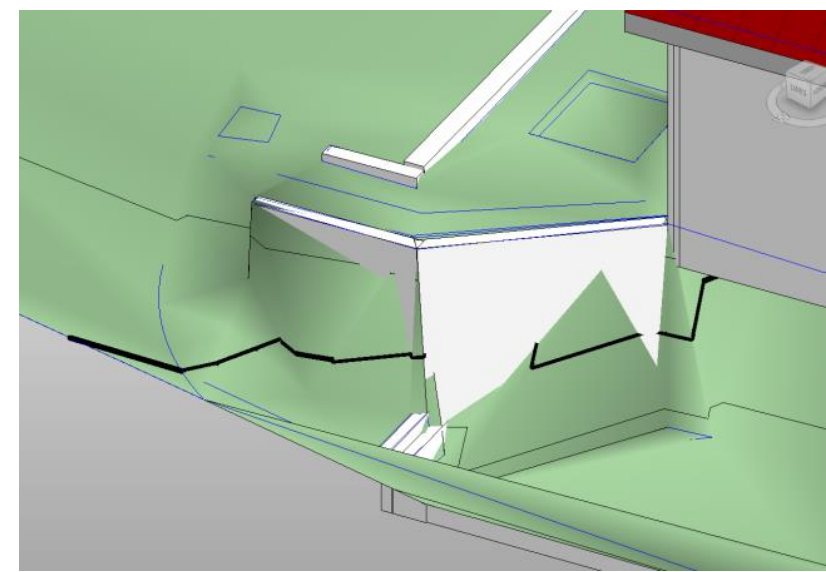

Figure 3 Terrain cuts elements and obstruct the view

3.3.2 Man-Made Objects: In contrast to elements of buildings, which in general follows geometrical restrictions like verticality, horizontality and rectangularity as well as constructional restrictions like the connection between walls and the floor or ceilings, landscape elements may have very individual shapes and thus does not meet the typical BIM modeling concepts.

Within this project, complex retaining walls had to be modeled, which did not follow the common restrictions of the general wall elements in Revit. The retaining walls are tilted, the bottom of the wall is not connected to a horizontal level but follows the irregular inclined terrain and the top of the wall is stepwise and not topological connected to another element. Such complex retaining walls cannot be modeled using the pre-defined wall elements, but only using generic BIM elements with just a few standardized properties. Therefore, it is extremely time consuming in contrast to use pre-defined elements. Figure 4 shows a completed retaining wall, which is well adjusted in the terrain.
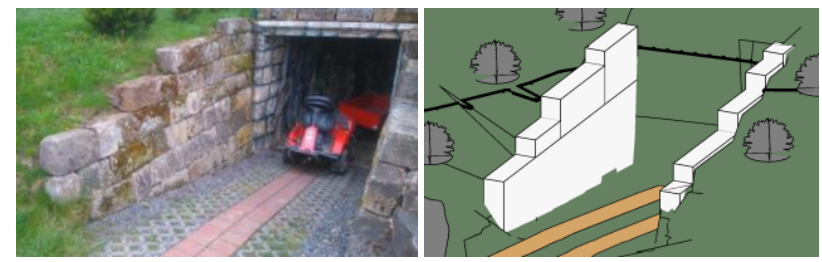

Figure 4 (l) real garage entrance (r) virtual garage entrance

In addition, horizontal elements of the landscape do not meet the general BIM modeling concept for building elements. Objects like terraces, paths, stairs, or parking areas typically have a gradient to realize water outflow. In contrast, pre-defined BIM elements like foundation or base plates and ceilings are typically horizontal in BIM. Similar to retaining walls, inclined landscape elements can be modeled using generic BIM elements with just a few standardized properties.

Beside the shape, another characteristic of landscape objects in contrast to building elements is that they are often located unattached and topologically independent to other elements, which led to difficulties with the BIM modeling concept of relative positioning of elements and using horizontal levels and construction lines. Thus, it was necessary either to create a 
horizontal level for each element in order to have a base layer for the vertical placement or to create only one horizontal level and the relative height must be calculated for each element, in order to vertically locate the element.

As a first try, the Site Designer for Revit has been used to create landscape objects like paths, roads and parking slots. However, during the work with the Site Designer, it arose more problems than solutions. If model lines were not correctly located on the terrain, it was not possible to model landscape objects on it. In addition, paths or other elements can be modeled only surfacebased. In the course of the project, too many failures occurred so that the work with the Site Designer was stopped. Similar experiences with the Site Designer has been made by RÜCKER (2017).

3.3.3 Plants: As an important element for landscape modeling are plants. The default family library of Revit includes some pre-defined trees, shrubs and hedges. There is also the opportunity to download some user-defined plants from the Internet. However, plants are only modeled in a photorealistic way without their underground laying root system. Furthermore, there are no defined properties for plants like the age, the width of treetop, the circumference or other parameter, which are important for the maintenance. Especially for the management phase, there is a need of such information as well as the opportunity to create three-dimensional plants including their root system. Beside landscape architecture, other domains will also benefit from having the surrounding plants in their projects, e.g. to analyze different circumstances like shadowing, temperature, wind behavior, underground situations, etc.

\subsection{Georeferencing}

3.4.1 Authoring Software: Although, Revit was developed for the architecture and construction domain working with local project coordinates, there are possibilities to georeference the project coordinates to a geodetic CRS. However, there is no standardized procedure to uniquely identify the coordinate system within the project by using a so-called Spatial Reference System Identifier (SRID). A SRID is a unique value used to unambiguously identify projected, un-projected and local spatial coordinate system definitions and is used in GIS software. That means, that all involved stakeholders and operators working with a BIM project must be informed about the CRS definition, in order to be able to locate the project on its true position on the earth. There are three methods to georeference a BIM project in Revit, which are from a geodetic point of view more or less practicable and partially reliable (KADEN et. al. 2017).

For the georeferencing in Revit 2017, the survey point and the project base point can be used. For this purpose, coordinates are assigned to either a local coordinate system or a geodetic CRS. The project base point defines the origin of the project coordinate system. The project coordination system is defined automatically when a project is created and is used to relatively model the building elements with measures. Object coordinates that reference the project coordinate system are displayed relative to the project base point. The project base point can be any logical point, e.g. the intersection of grid lines or a specific building corner and can be used to define a local coordinate system. The project base point is symbolized as a blue-circle with cross symbol. The survey point allows the correct position of the project geometry in other (higher) coordinate systems. It reference either the origin or a survey point in a local survey point system (LSS) or in a geodetic CRS. Thus, the survey point defines the origin of a "shared coordinate system". It is symbolized as a blue triangle labeled with "Survey Point". The three parameters of the transformation (northing, easting, azimuth) are shown as attributes at the project base point.

A second method to georeference a Revit project is to use coordinates of a CAD data set like a DWG or DXF file. Location plans of the planning sites from surveyors are usually based on an official CRS, e.g. ETRS89, which can be adopted for the project within Revit. Therefore, the CAD file can be linked to a Revit project. The coordinates of the linked project become the shared coordinates of the Revit project, based on the position of the linked project instance in the Revit project. However, there is no change to the internal coordinates of the Revit project. Furthermore, the Revit project also acquires the true north information (azimuth angle) from the linked CAD project. The origin of the coordinates of the linked project becomes the origin of the shared coordinates within the Revit project.

From a geodetic point of view, the third option is the most native way to georeference a Revit project. Two control points, e.g. building corners, with known coordinates in the higher coordinate system are used to transform the Revit project geometry into a CRS. However, this function is only available within the Autodesk Point Layout (APL) Plug-In, which is for acquiring stake out data for surveyors.

3.4.2 Industry Foundation Classes (IFC): In order to understand how project coordinates can be georeferenced, it is first necessary to consider the placement concept of geometries in the IFC scheme. Following the inheritance hierarchy in the IFC model, it can be seen that all objects which have a spatial context are derived from the class IfcProduct. This class has two attributes, which are required for the placement and geometry presentation. The ObjectPlacement attribute uses the IfcObjectPlacement class to establish the relationship to the different object placement options in the model.

According to the IFC specification, a placement can be absolute, relative or in a defined grid (BSI 2016). In the IFC model, absolute placement does not mean that the geometry is placed using a geodetic CRS, rather it is placed w.r.t. the World Coordinate System (WCS) of the project, which is defined within the IFC file using the class IfcGeometricRepresentationContext. A relative placement of an object refers to a placement of another object, usually a superior object, e.g. the placement of a wall is relative to the coordinate system of the respective storey and the storey is again placed relative to the coordinate system of the building. Regarding to the IFC specification, the most superior object in the project, e.g. the spatial element IfcSite, should be placed absolute w.r.t. the project WCS. All other objects, which are hierarchically below the site object, e.g. IfcBuilding, then follow the relative positioning w.r.t. the local system of the IfcSite. Thus, the IFC objects cannot directly be placed using a geodetic CRS. However, the project WCS can be assigned to the geodetic CRS using the IfcCoordinateOperation element (Figure 5).

The class consists of two attributes referring the source and target coordinate systems of the coordinate operation. The source coordinate system can be either the project WCS or - in case the project WCS is already coherent to a CRS - a geodetic CRS. For the target system of the coordinate operation, a projected CRS can be defined. According to the IFC 
specification, the attribute Name is mandatory and should represent a Spatial Reference System Identifier (SRID) according to the European Petroleum Survey Group (EPSG) code. However, the definition of the CRS using a EPSG code is no explicitly defined in IFC. Depending on the author of the IFC file, the attribute Name can include "EPSG:1234", "1234" or "Name EPSG:1234". The coordinate operations between the source and the target coordinate system includes the positioning of the origin of the source coordinate system within the target system as well as a rotation in the $\mathrm{X}, \mathrm{Y}$ plane.

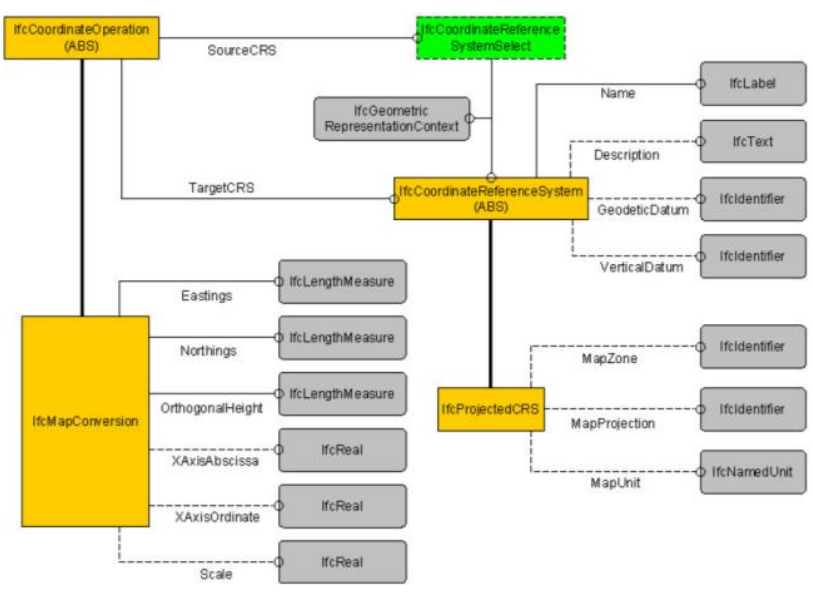

Figure 5 EXPRESS-G Diagram of the IFC (version 4) coordinate operation model

\section{FORMALISATION OF LANDSCAPE ELEMENTS}

\subsection{Concept of Level of Information Need}

BIM models offer enormous possibilities (3D visualization, intelligent objects, many items of data, automated analysis) and thus raise very high expectations of the appointing party (information receiving), which the delivered model of the appointed party (information sending) may not always fulfil. The communication and the contractual frame of the information requirements (IR) for the level of detail/development (LOD) frequently lead to misunderstandings in practical work because each specialist uses different terms. Actually, often it is not clear what the term "detailing" means.

A pan-European terminology for describing the "Level of Information Need (LOIN)" is currently developed in CEN / TC 442 / WG 2 / TG1, the anticipated number of this standard is EN 17412 (BOLPAGNI 2019). The term "Level of Information Need" changes the perspective: LOIN addresses the expectation (need) of the appointing party as information requirements (IR). The European Standard deliberately does not use a metric (LOD100, LOD200, etc.) to avoid competing with national standards. Instead, the standard provides a framework for describing the required granularity and structure of each object type: level of geometry (LOG), level of information (LOI) and Level of Documentation (DOC).

Today the geometric level of detail (LOG) is implicitly defined with the drawing scale. In the model-based work according to the LOIN standard, the "detailing" has to be set more complexly: detail (symbolic, simplified, detailed), dimensionality, location (relative, absolute), appearance and parametric behaviour are specified in the LOG. In addition, the type of object identification (name, identifier), and the type and structure of object classification and attribution must be specified using the Level of Information (LOI). The third Level of Documentation (DOC) governs the level of detail and the amount of (external) documents delivered in addition to the virtual building model. Examples are room books, inventory lists, written reports, datasheets, manuals, photos or detailed drawings.

In analogy with (ACE 2019) we propose a Level of Reliability (LOR) to consider the data quality of exterior objects in terms of reliability for the as-is model (negative LOR), and planned landscape model (positive LOR) to state whether the exterior object is for visualisation only or are result of a carefully undertaken planning process by landscape architects:

LOR -2: As-Is, objects / coverage from external geodata (GIS)

LOR -1: As-Is, objects/coverage measured or checked on site (site survey)

LOR 0: No planning of exterior objects

LOR 1: Exterior objects planned as sketch, for visualisation only

LOR 2: Planned in detail

LOR 3: Checked with regulations

LOR 4: Ready for Contractors/planting

LOR 5: As-built

\subsection{Concept of a property server for PDT's and geoPDT's}

Product data templates (PDT) are a useful information provider for the exchange of a specific purpose for a construction object in the production, design, inception, brief, operation and demolition of facilities. In addition, it provides manufacturers a standardized data structure that can be applied to any internal system and/or process of handling product data (ISO/DIS 23387 2019).

Referring to PDT's, we propose to use the concept of a property server, which is connected to the buildingSMART data dictionary (bSDD) for unified product descriptions also for landscape modeling (exterior objects). This concept includes standard PDT's for manufactures, but also geoPDT's for land surveyors or geo data providers. The idea of this concept arose because many manufacturers annotate the same products with different names. It serves to create a uniform product description and helps manufacturers to attribute important properties of a product.

Figure 6 shows the workflow of the concept. Manufacturers can request the property server for "needed attributes" of a specific product. As a result, they get back a product data template (PDT) of the requested product with its important properties. These properties were collected and defined by standardization bodies or beforehand and implemented as the PDT's. The manufacturers adds the values to the requested properties and thus specifies a product data sheet (PDS) according to the information requirements (IR). The completed PDS of the manufacturer can validated against the PDTs. Eventually the virtual building model (AIM, PIM, GIS) contains the semantically standardized attributes. 


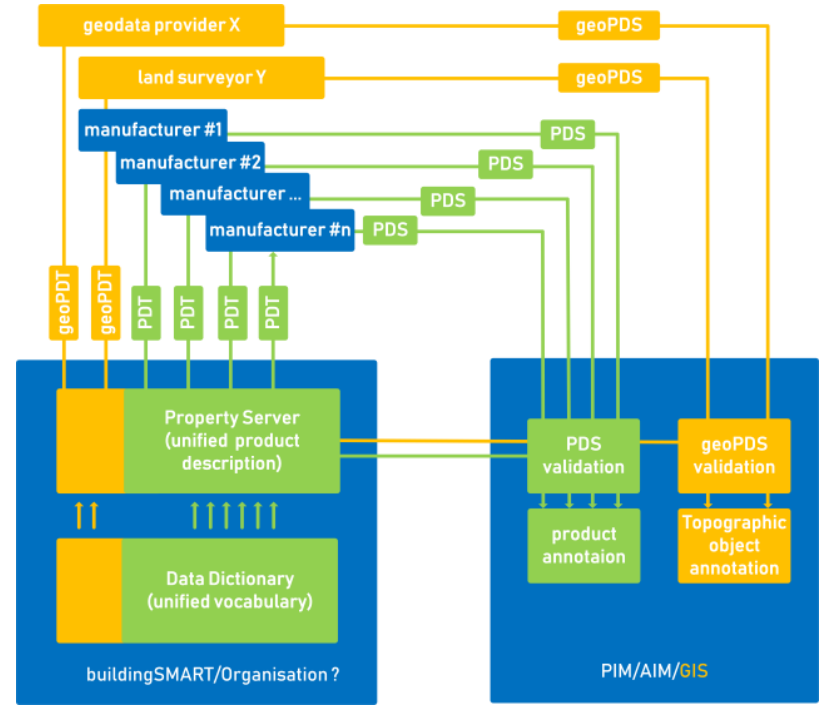

Figure 6 Product Data Sheets (PDT) for uniform description of construction products (green) and geodetic products (orange)

We propose to extend this system architecture especially for land surveyor and geodata provider in order to unify information about landscape conditions. For example, geoPDTs gives the opportunity to describe surfaces of pathways, general information of located vegetation, etc. Geo data provider and land surveyors provide descriptive information about the built environment, e.g. terrain model, location and elevation plan or 3D model. The PDT system architecture could be used to leverage the distributed machine-readable templates for ordering and validating geospatial products in BIM projects.

\section{CONCLUSION AND FUTURE WORK}

The feasibility study has shown that the general modeling concepts of BIM are perfectly suitable for representing planned buildings, but are often a drawback for modeling individual landscape object, especially as-built structures. Using the widespread BIM software Revit 2017, one of the main difficulties occurred in the project is the missing opportunity to introduce break lines for terrain modeling. Without break lines, terrain often intersect or even overlay landscape constructions like retaining walls, terraces or paths and thus does not represent the topography correctly.

Individual landscape objects are often neither vertically nor horizontally and does not be relatively placed to horizontal planes, construction lines, or other elements and thus collide with the basic BIM modeling paradigm. When modeling objects such as tilted retaining walls and terraces or paths, pre-defined BIM elements are not suitable to represent such complex landscape. Such objects can be modeled only using generic elements, which means that the use of the clear defined BIM elements is not possible. In addition, the concept of vertical positioning of elements using horizontal base levels is not appropriate for locating landscape objects since they usually all refer to different heights and thus requires separate base levels or individual height offsets.

Hence, detailed expert knowledge of data modeling, software and formats is required to realize such a project. A number of necessary workarounds were extremely time consuming and lead to a total amount of about 400 hours of work in the project.
Moreover, some specific objects like playground equipment and other landscape furniture has not been modeled due to its complexity and the lack of appropriate BIM elements and concepts. A cutout of the result of the integrated building and landscape objects can be seen in figure 7, however, the presented project is still in an early stage of development regarding the development of appropriate IFC concepts.

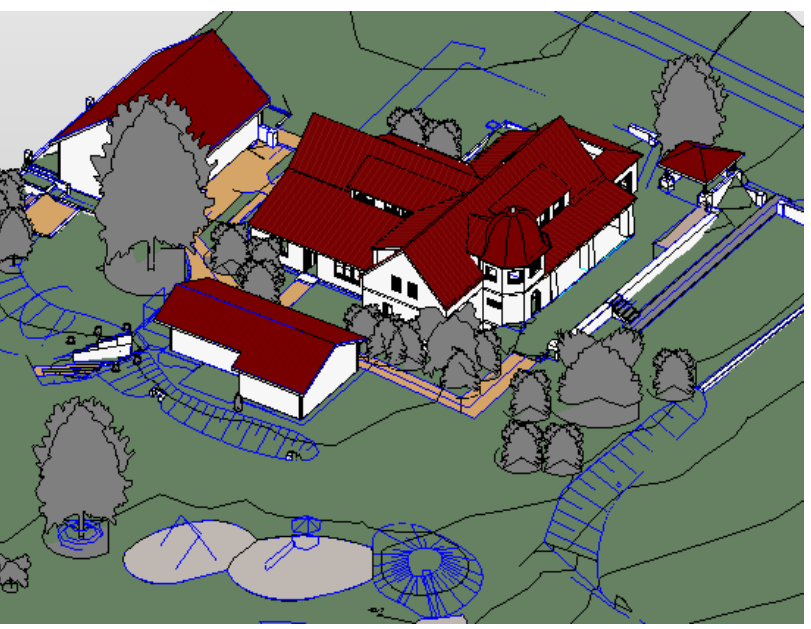

Figure 7 Result of BIM-able landscape elements

An integrated planning including landscape is important for automation, collaboration, saving cost and time, reducing failures and to delivery of a comprehensive amount of information (AHMAD 2012). However, the feasibility study project has shown that modeling landscape objects in the BIM authoring tool Revit as well as the export to IFC is still not straightforward and requires further research. Moreover, the interoperability between different data formats is quite challenging w.r.t the loos of information. Therefore, future work comprises a study regarding linking of elements within different data sets and formats, e.g. CityGML and LandInfra, using link models. Nonetheless, the aim of the project is the componentbased modeling of landscape elements in order to take advantage of the BIM methodology such as the estimation of construction material and the derivation of building expenses.

The buildingSmart International working group "IFC for Site, Landscape, and Urban Planning" which was founded in December 2018 coordinates appropriate work. As the first step, this project was to investigate the suitability of basic BIM modeling concepts for complex and individual landscape objects. Future work will contain the precise definition and description of properties of relevant landscape elements, that means, the proposed spreadsheet templates of the bSI working group have to reviewed and accepted by the working group. On that basis, the main task is to develop standardized IFC property sets and IFC schema definition of new IFC landscape elements.

\section{REFERENCES}

Abdirad, H. and Lin, K. (2015). Advancing in Object-based Landscape Information Modeling: Challenges and Future Needs. American Society of Civil Engineering; Computing in Civil Engineering 2015: pp. 548-555. http://ascelibrary.org/doi/abs/10.1061/9780784479247.068 (2019-04-23) 
ACE (2019). ACE Guide: An Introduction to BIM. Architects' Council of Europe, Brussels, Belgium. https://www.acecae.eu/uploads/tx_jidocumentsview/ACE_BIM_GUIDE_2019_ A4_EN_WEB.pdf (2019-05-13)

Ahmad, A. M. and Aliyu, A.A. (2012). The Need for Landscape Information Modeling (LIM) in Landscape Architecture. Paper presented at the Digital Landscape Architecture Conference, Bernburg, Germany.

http://citeseerx.ist.psu.edu/viewdoc/download?doi=10.1.1.470.9 995\&rep=rep1\&type=pdf (2019-05-03)

BMVI (2015). Stufenplan Digitales Planen und Bauen Einführung moderner, IT-gestützter Prozesse und Technologien bei Planung, Bau und Betrieb von Bauwerken. Bundesministerium für Verkehr und digitale Infrastruktur, Berlin, Germany.

https://www.bmvi.de/SharedDocs/DE/Publikationen/DG/stufen plan-digitales-bauen.pdf?__blob=publicationFile (2019-05-08)

Bolpagni, Marizia (2019). CEN TC 442 WG2, Building Information Modelling Levels of Information Need, CEN TG 1 status report, 12.03.2019

BSI (2016). Industry Foundation Classes. Version 4 Addendum 2, Chapter 8.18.3.1, buildingSMART International Ltd. http://www.buildingsmart-tech.org/ifc/IFC4/Add2/html/ (2019-05-13)

Clemen, C. (2019). Modellbasierte Vermessung mit den IFC Heute am Beispiel topographischer Modelle (Lage- und Höhenplan). Seminar of Bildungswerk VDV, Fulda, Germany.

DDBIM (2019). Downloads. Zentrum für Angewandte Forschung und Technologie e.V, Dresden, Germany. http://www.dd-bim.org/?page_id=31 (2019-05-05)

Designing Buildings Wiki (2019). Product Data Sheet. https://www.designingbuildings.co.uk/wiki/Product_Data_Shee $\mathrm{t}(2019-05-03)$

IFC INFRA (2019). IFC für den Infrastrukturbereich Ongoing Projects: IFC-Bridge, IFC-Road, IFC-Rail, IFCTunnel. Bundesministerium für Verkehr und digitale Infrastruktur. http://ifcinfra.de/ (2019-05-03)

ISO/DIS 23387 (2019). Bauwerksinformationsmodellierung (BIM) - Datenvorlagen für Bauobjekte während des Lebenszyklus eines baulichen Vermögensgegenstandes Konzepte und Grundsätze. DIN EN ISO 23387:2019-04 Entwurf, doi:10.31030/3042021

Kaden, R. and Clemen, C. (2017). Applying Geodetic Coordinate Reference Systems within Building Information Modeling (BIM). Faculty of Geoinformation, Dresden University of Applied Sciences.

Landscape Institute (2016). PDT Store. Product Data Template store of Landscape Institute, Great Britain, https://www.landscapeinstitute.org/technical-resource/pdt-store/ (2019-05-03)

Ouellette, J. (2018). IFC for Site, Landscape, and Urban Planing. Activity Proposal, buildingSMART International. https://drive.google.com/file/d/194CwV2JLzdVga-

QdpoqJmRTL1oSQXgs5/view (2019-04-23)
Rücker, N. (2017). Modellierung und Datenaustausch von Geländemodellen und topographischen Daten im Building Information Modeling (BIM). Master Thesis, Faculty of Geoinformation, Dresden University of Applied Sciences.

Wik, K. H.; Sekse, M.; Enebo, B. A.; Thorvaldsen, J. (2018). BIM for Landscape: A Norwegian Standardization Project. Full paper of bar bakke landskapsarkitekter AS, Oslo, Norway. https://gispoint.de/fileadmin/user_upload/paper_gis_open/DLA _2018/537642026.pdf (2019-05-03)

Revised August 2019 